\title{
Treatment of Aluminium Phosphide Poisoning with a Combination of Intravenous Glucagon, Digoxin and Antioxidant Agents
}

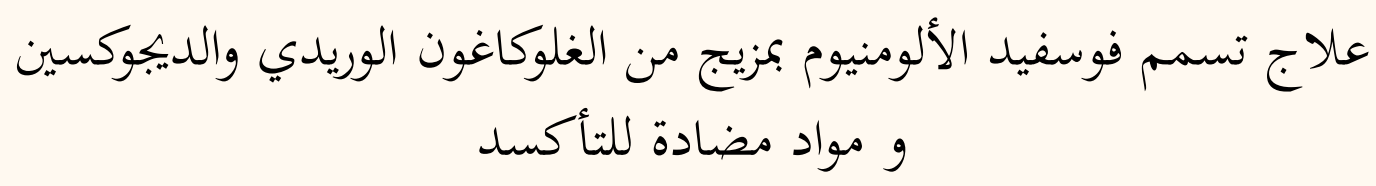

زهرة أجابيان و أوميد مهربور

ABSTRACT: Aluminium phosphide (AlP) is used to protect stored grains from rodents. It produces phosphine gas $\left(\mathrm{PH}_{3}\right)$, a mitochondrial poison thought to cause toxicity by blocking the cytochrome c oxidase enzyme and inhibiting oxidative phosphorylation, which results in cell death. AlP poisoning has a high mortality rate among humans due to the rapid onset of cardiogenic shock and metabolic acidosis, despite aggressive treatment. We report a 21-yearold male who was referred to the Afzalipour Hospital, Kerman, Iran, in 2015 after having intentionally ingested a $3 \mathrm{~g}$ AlP tablet. He was successfully treated with crystalloid fluids, vasopressors, sodium bicarbonate, digoxin, glucagon and antioxidant agents and was discharged from the hospital six days after admission in good clinical condition. For the treatment of AlP poisoning, the combination of glucagon and digoxin with antioxidant agents should be considered. However, evaluation of further cases is necessary to optimise treatment protocols.

Keywords: Aluminum Phosphide; Phosphine; Poisoning; Digoxin; Glucagon; Antioxidants; Case Report; Iran.

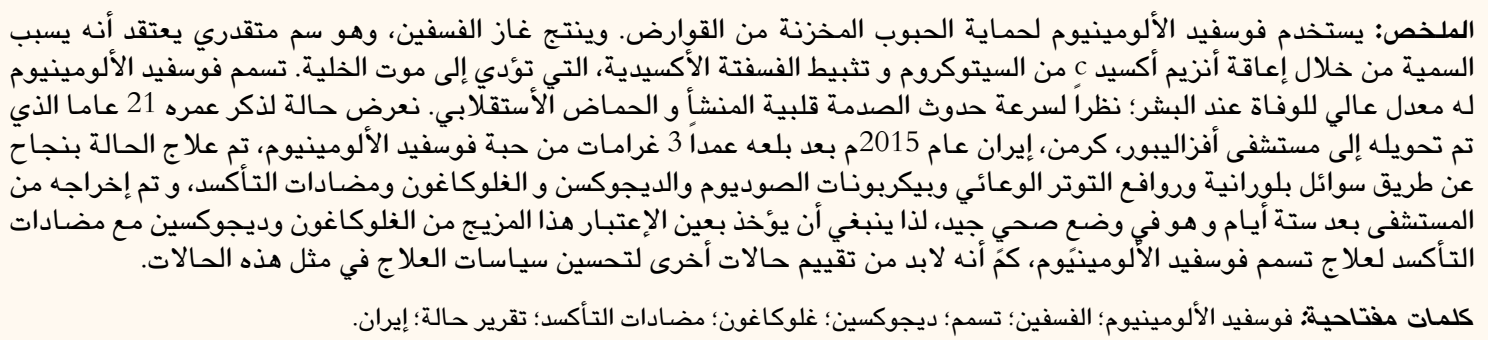

A LUMINIUM PHOSPHIDE (AlP) IS A VERY effective outdoor and indoor pesticide used for protecting stored grains from rodents and other pests. ${ }^{1}$ In Iran, AlP tablets are widely used for protecting rice against pests and so are traditionally called "rice tablets". 2 Phosphine gas $\left(\mathrm{PH}_{3}\right)$ is rapidly formed and released when AlP comes into contact with water or dilute acids, such as those found in the stomach, and is the fatal active form of the pesticide. ${ }^{3}$ The two main routes of acute toxicity due to AlP are the ingestion of AlP tablets and inhalation of released $\mathrm{PH}_{3}$. Although the exact mechanism of action of AlP is not clearly understood, $\mathrm{PH}_{3}$ is thought to induce toxicity by blocking the cytochrome c oxidase enzyme and inhibiting oxidative phosphorylation which eventually leads to myocyte death. ${ }^{1,2}$ AlP poisoning has a very high mortality rate (30-100\%) and survival is unlikely if more than $1,500 \mathrm{mg}$ is ingested; the lethal dose for an individual weighing $70 \mathrm{~kg}$ is $150-500 \mathrm{mg} .{ }^{1}$ Exposure to AlP is rarely accidental and the majority of cases of severe AlP poisoning are reportedly due to the deliberate ingestion of AlP tablets with suicidal intentions. ${ }^{2,3}$ Although there are reports of accidental inhalation of $\mathrm{PH}_{3}$ gas, especially among workers, AlP is known as a suicide poison with no effective antidote that can be easily bought. ${ }^{2}$

Presenting features of AlP intoxication include the rapid onset of shock, vomiting, nausea, retrosternal and epigastric pain, dyspnoea, anxiety, agitation and garlic-odour breath. ${ }^{3}$ An early sign of AlP poisoning is severe metabolic acidosis and hypotension, which leads to shock and tissue perfusion failure in the first couple of hours after ingestion due to cardiogenic shock and peripheral circulatory failure. ${ }^{1-4}$ Other cardiovascular complications include cardiac arrhythmias and acute myocardial infarctions. ${ }^{1}$ Profound circulatory collapse 
Table 1: Clinical and laboratory findings of a patient with aluminium phosphide poisoning

\begin{tabular}{|c|c|c|c|c|c|c|}
\hline \multirow[t]{2}{*}{ Finding } & \multicolumn{6}{|c|}{ Post-admission time in hours } \\
\hline & 0 & 2 & 12 & 24 & 48 & $144^{*}$ \\
\hline Blood pressure in $\mathrm{mmHg}$ & $85 / 40$ & $90 / 60$ & $98 / 70$ & $100 / 40$ & $120 / 85$ & $110 / 70$ \\
\hline Pulse rate in beats/minute & 130 & 120 & 112 & 115 & 98 & 85 \\
\hline Respiratory rate in breaths/minute & 16 & 17 & 18 & 12 & 14 & 16 \\
\hline Temperature in ${ }^{\circ} \mathrm{C}$ & 36.7 & 36.0 & 37.1 & 37.2 & 36.8 & 37.3 \\
\hline $\mathrm{O}_{2}$ saturation in $\%$ & 93 & 92 & 90 & 95 & 97 & 96 \\
\hline $\mathrm{PaCO}_{2}$ in $\mathrm{mmHg}$ & 28.5 & 26.8 & 33.6 & 30.2 & 41.7 & 47.6 \\
\hline $\mathrm{pH}$ & 7.18 & 7.20 & 7.43 & 7.37 & 7.45 & 7.43 \\
\hline $\mathrm{HCO}_{3}$ in $\mathrm{mmol} / \mathrm{L}$ & 11.7 & 11.1 & 22.7 & 17.6 & 29.7 & 32.5 \\
\hline $\mathrm{BE}$ in $\mathrm{mmol} / \mathrm{L}$ & -17.6 & -16.7 & -0.2 & -5.6 & 5.8 & 8.1 \\
\hline $\mathrm{Na}$ in meq/L & 135 & - & - & 137 & 135 & 140 \\
\hline $\mathrm{K}$ in meq/L & 4.6 & - & - & 3.8 & 3.7 & 3.8 \\
\hline WBC & 14,300 & - & - & - & - & 9,200 \\
\hline Hct & 45.3 & - & - & - & - & 34.5 \\
\hline PT & 17 & - & - & - & - & 16 \\
\hline INR & 1.6 & - & - & - & - & 1.1 \\
\hline Blood glucose in mg/dL & 133 & - & - & 141 & - & 123 \\
\hline BUN in mg/dL & 20 & - & - & 40 & - & 24 \\
\hline Creatinine in $\mathrm{mg} / \mathrm{dL}$ & 1.7 & - & - & 1.4 & - & 1.1 \\
\hline
\end{tabular}

is commonly associated with AlP poisoning; this is believed to be due to the direct effect of $\mathrm{PH}_{3}$ on the heart cells. ${ }^{5}$ Cardiogenic shock is one of the main causes of death. ${ }^{5,6}$ There is currently no known antidote for this poison and most treatment modalities are not successful; however, the effective treatment of AlP poisoning using an intra-aortic balloon pump (IABP) and digoxin has previously been reported. ${ }^{5,6}$ In addition, other researchers have reported that glucagon, digoxin or antioxidants administered individually to poisoned patients have had a beneficial effect. $^{3,5}$ This report is the first to present the combined administration of glucagon, digoxin and antioxidants in the management of a patient with AlP poisoning.

\section{Case Report}

A 21-year-old man was referred to the Afzalipour Hospital, Kerman, Iran, in 2015 after the intentional ingestion of a $3 \mathrm{~g}$ rice tablet containing AlP. The patient had swallowed the tablet whole with one glass of water, without crushing the AlP tablet into a powder. He had vomited approximately 45 minutes after ingesting the tablet and was admitted to a local hospital four hours later. At this point, he was completely awake and complained of abdominal and retrosternal pain and severe thirst. He had previously had a ventricular septal defect which had been repaired five years earlier. At presentation to the local hospital, the patient's initial vital signs were as follows: blood pressure of 90/60 mmHg; pulse rate of 140 beats/minute; respiratory rate of 18 breaths/minute; axillary temperature of $36.4{ }^{\circ} \mathrm{C}$; and oxygen saturation of $95 \%$ in ambient air.

Approximately 10 hours after ingestion of the tablet, the patient was referred to the Afzalipour Hospital, the main referral toxicology centre in Kerman province. ${ }^{7}$ He was confused and his vital signs were as follows: blood pressure of $85 / 40 \mathrm{mmHg}$; pulse rate of 130 beats/minute; respiratory rate of 16 breaths/minute; axillary temperature of $36.7{ }^{\circ} \mathrm{C}$; and oxygen saturation of $93 \%$ in ambient air. Arterial blood gas analysis indicated that his $\mathrm{pH}$, partial pressure of carbon dioxide, bicarbonate $\left(\mathrm{HCO}_{3}\right)$ and 
base excess were 7.18, $28.5 \mathrm{mmHg}, 11.7 \mathrm{mmol} / \mathrm{L}$ and $-17.6 \mathrm{mmol} / \mathrm{L}$, respectively. Electrocardiography revealed that the patient had sinus tachycardia. Using bedside echocardiography, the left ventricular ejection fraction was $35 \%$. Serial vital signs and laboratory findings over time are presented in Table 1.

The patient was prescribed 44 milliequivalents of sodium bicarbonate every 15 minutes until the metabolic acidosis was corrected. He was also given an intravenous infusion of normal saline and vasopressors; additionally, $1 \mathrm{mg}$ of glucagon was administered intravenously every 5-10 minutes until his blood pressure normalised after a total of $4 \mathrm{mg}$ of glucagon. This was followed by a $4 \mathrm{mg} /$ hour slow intravenous infusion of glucagon. Subsequently, digoxin ( $0.5 \mathrm{mg}$ initially followed by $0.25 \mathrm{mg}$ every six hours for 24 hours and $0.25 \mathrm{mg}$ daily thereafter), magnesium sulphate ( $1 \mathrm{~g}$ initially followed by $1 \mathrm{~g}$ every six hours), $10 \%$ calcium gluconate (1 g initially followed by $1 \mathrm{~g}$ every six hours), hydrocortisone (200 mg initially followed by $200 \mathrm{mg}$ every six hours), vitamin C $(1,000 \mathrm{mg}$ every 12 hours via slow intravenous infusion), vitamin E (400 units intramuscularly) and $\mathrm{N}$-acetylcysteine (NAC; $140 \mathrm{mg} / \mathrm{kg}$ orally as a loading dose followed by $70 \mathrm{mg} / \mathrm{kg}$ orally every 4 hours for up to 17 doses) were administered. With the improvement of the metabolic acidosis and stabilisation of the patient's vital signs, all medications were gradually tapered off. The patient was discharged from the hospital six days after admission in good clinical condition and completely symptom-free. He did not require tracheal intubation at any point during admission. Repeat echocardiography at discharge revealed that the left ventricle ejection fraction was $50 \%$.

\section{Discussion}

AlP induces oxidative stress and boosts the extramitochondrial release of free oxygen radicals that lead to lipid peroxidation and protein denaturation of the cell membrane in various organs. ${ }^{1} \mathrm{PH}_{3}$ inhibits mitochondrial cytochrome $\mathrm{C}$ oxidase and catalase, induces superoxide dismutase and reduces the concentration of glutathione in AlP-poisoned patients, which leads to the generation of superoxide radicals and cellular peroxides. ${ }^{1,2}$ Cellular injury subsequently occurs via lipid peroxidation and other oxidant mechanisms, such as protein denaturation of the cell membrane and hypoxic cell damage. ${ }^{8}$ The major lethal consequences of AlP ingestion (i.e. profound circulatory collapse) are reportedly secondary to the toxins generated which directly affect cardiac myocytes and cause fluid loss and adrenal gland damage. ${ }^{1,3,4}$ The main causes of cardiogenic shock in AlP poisoning have been suggested to be the inhibition of cytochrome $\mathrm{C}$ oxidase, secondary toxic myocarditis and AlP-induced oxidative stress that lead to pump failure and cardiac arrest. ${ }^{1}$ There is currently no specific antidote for AlP poisoning and supportive therapy is the mainstay of treatment for poisoned patients. ${ }^{3,5}$

Antioxidant therapy using vitamins $\mathrm{E}$ and $\mathrm{C}$ and NAC may theoretically have a therapeutic role in acute AlP poisoning, as one of the main mechanisms of AlPinduced toxicity is oxidative stress. Some researchers have suggested the use of these agents-especially NAC - to treat AlP poisoning. ${ }^{9}$ In the current case, the patient was treated successfully with vitamins $\mathrm{E}$ and $C$ and NAC. The treatment of cardiogenic shock caused by AlP poisoning with digoxin and an IABP has been suggested for mechanical support of the heart in toxic myocarditis and refractory shock; this approach has also had positive responses. ${ }^{5,6}$ Tehrani et al. found that hospital stay duration and rates of intubation, ventilation and mortality were significantly lower among AlP-poisoned patients who received NAC in comparison to controls. ${ }^{9}$ In addition, there is some evidence suggesting that glucagon is useful for the treatment of cardiogenic shock..$^{10,11}$ Glucagon is an antidote for $\beta$-blocker poisoning but is also used to treat cardiogenic shock due to verapamil and, sometimes, imipramine. ${ }^{10}$ It has been postulated that glucagon activates adenylate cyclase at a different site to $\beta$-adrenergic agents, resulting in an increase in cyclic adenosine monophosphate; this increases the calcium pool available for release during depolarisation and contractility. ${ }^{11,12}$ Glucagon can also increase heart rate but has no effect on arterial pressure; thus, it has been reportedly useful in increasing mean blood pressure and heart rate in amitriptyline toxicity, although it is still unclear whether glucagon increases blood pressure. ${ }^{13}$ Glucagon receptors in the ventricular myocardium cause its inotropic effects. ${ }^{14}$ Thus, glucagon is a probable antidote for AlP poisoning by potentially increasing blood pressure and heart rate. Moreover, treating cardiogenic shock with glucagon may result in enhanced tissue perfusion. ${ }^{11}$ A previous case report described the successful treatment of a woman with AlP poisoning in Kerman, Iran, and concluded that the early administration of glucagon to AlP-poisoned patients in refractory shock may be beneficial. ${ }^{15}$

In addition to routine supportive treatments, managing the two main hazards of toxicity-oxidative stress and cardiogenic shock leading to circulatory collapse and lactic acidosis-is essential for the successful treatment of AlP poisoning. For this reason, agents with antioxidant properties such as vitamins $\mathrm{E}$ and $\mathrm{C}$ and $\mathrm{NAC}$ were administered to the patient in the 
current case as well as glucagon and digoxin to allow for better tissue perfusion. Since the sites of entrance and accumulation of calcium ions within the cell are different, glucagon and digitalis have synergistic inotropic effects. ${ }^{14}$ Coadministration of glucagon and digoxin is more effective than utilising each alone. ${ }^{16}$ Due to the short duration of action, prolonged continuous infusion of glucagon is necessary. ${ }^{12}$ Although alternative therapies such as angiotensin-converting enzyme inhibitors, intravenous diuretics and other intravenous inotropes are usually safer and more effective in cases of acutely decompensated heart failure, these treatments are less effective for patients with AlP poisoning. ${ }^{5}$ Successful treatment in the current case with glucagon and digoxin suggests that the concurrent use of high doses of these two agents may be useful in the treatment of AlP poisoning; however, this finding needs to be confirmed by further studies. The patient in the present case suffered from late vomiting; Louriz et al. observed that vomiting is a common symptom of AlP poisoning and that a lack of vomiting is a poor prognostic factor. ${ }^{17}$

In the present case, levels of paraoxonase 1 as well as the total antioxidant and total oxidant statuses and oxidative stress index were not evaluated. These are important to determine the patient's oxidant and antioxidant status. Previous studies have demonstrated that IABPs are another excellent treatment modality in cases of AlP poisoning;, ${ }^{1,6}$ the addition of an IABP to the treatment protocol used in the present case is recommended, especially in severe cases of AlP poisoning. However, it is important to bear in mind that IABPs are not available at all poisoning centres. The authors of this report recommend that other strong antioxidants such as superoxide dismutase and intracellular antioxidants like tempol should be used when treating cases of AlP poisoning.

\section{Conclusion}

A combination of glucagon and digoxin with antioxidant agents was used to successfully treat a patient with AlP poisoning. However, the clinical significance of this approach requires further consideration and evaluation in order to optimise management protocols for AlP poisoning.

\section{References}

1. Mehrpour O, Jafarzadeh M, Abdollahi M. A systematic review of aluminium phosphide poisoning. Arh Hig Rada Toksikol 2012; 63:61-73. doi: 10.2478/10004-1254-63-2012-2182.

2. Mehrpour O, Singh S. Rice tablet poisoning: A major concern in Iranian population. Hum Exp Toxicol 2010; 29:701-2. doi: $10.1177 / 0960327109359643$.

3. Gurjar M, Baronia AK, Azim A, Sharma K. Managing aluminum phosphide poisonings. J Emerg Trauma Shock 2011; 4:378-84. doi: 10.4103/0974-2700.83868.

4. Mehrpour O, Keyler D, Shadnia S. Comment on aluminum and zinc phosphide poisoning. Clin Toxicol (Phila) 2009; 47:838-9. doi: $10.1080 / 15563650903203684$

5. Mehrpour O, Farzaneh E, Abdollahi M. Successful treatment of aluminum phosphide with digoxin: A case report and review of literature. Int J Pharmacol 2011; 7:761-4. doi: 10.3923/ ijp.2011.761.764.

6. Mehrpour O, Amouzeshi A, Dadpour B, Oghabian Z, Zamani N, Amini S, et al. Successful treatment of cardiogenic shock with an intraaortic balloon pump following aluminium phosphide poisoning. Arh Hig Rada Toksikol 2014; 65:121-6. doi: 10.2478/10004-1254-65-2014-2393.

7. Mehrpour O, Abdollahi M. Poison treatment centers in Iran. Hum Exp Toxicol 2012; 31:303-4. doi: 10.1177/096032711 0392086.

8. Mehrpour O, Abdollahi M, Sharifi MD. Oxidative stress and hyperglycemia in aluminum phosphide poisoning. J Res Med Sci 2014; 19:196.

9. Tehrani H, Halvaie Z, Shadnia S, Soltaninejad K, Abdollahi M. Protective effects of $\mathrm{N}$-acetylcysteine on aluminum phosphideinduced oxidative stress in acute human poisoning. Clin Toxicol (Phila) 2013; 51:23-8. doi: 10.3109/15563650.2012.743029.

10. White CM. A review of potential cardiovascular uses of intravenous glucagon administration. J Clin Pharmacol 1999; 39:442-7. doi: 10.1177/009127009903900502.

11. Arefi M, Tabrizchi N. Could glucagon be a therapeutic option in the management of acute aluminium phosphide toxicity? Endocrinol Metab Syndr 2012; 1:5. doi: 10.4172/2161-1017. 1000109.

12. Pollack CV Jr. Utility of glucagon in the emergency department. J Emerg Med 1993; 11:195-205. doi: 10.1016/0736-4679(93) 90519-D.

13. Love JN, Howell JM. Glucagon therapy in the treatment of symptomatic bradycardia. Ann Emerg Med 1997; 29:181-3. doi: 10.1016/S0196-0644(97)70327-5.

14. Gonzalez-Muñoz C, Nieto-Cerón S, Cabezas-Herrera J, Hernández-Cascales J. Glucagon increases contractility in ventricle but not in atrium of the rat heart. Eur J Pharmacol 2008; 587:243-7. doi: 10.1016/j.ejphar.2008.04.001.

15. Torabi M. Successful treatment of aluminium phosphide poisoning: A case report. Iran J Pharmacol Ther 2013; 12:77-9.

16. Lvoff R, Wilcken DE. Glucagon in heart failure and in cardiogenic shock: Experience in 50 patients. Circulation 1972; 45:534-42. doi: 10.1161/01.CIR.45.3.534.

17. Louriz $M$, Dendane $T$, Abidi $K$, Madani N, Abouqal $R$, Zeggwagh AA. Prognostic factors of acute aluminum phosphide poisoning. Indian J Med Sci 2009; 63:227-34. doi: 10.4103/0019-5359.53386. 